\title{
Development of Electrochemical Oscillation Method for Identification of Prunus persica, Prunus davidiana, and Prunus armeniaca Nuts
}

\author{
Shuai Yan ${ }^{1 \dagger}$, Yinzi Yue ${ }^{1 \dagger}$, Lianlin Su${ }^{2}$, Min Hao ${ }^{3}$, Xiaopeng Wang ${ }^{1 *}$ and Ting Zuo ${ }^{4 *}$ \\ ${ }^{1}$ Suzhou TCM Hospital Affiliated to Nanjing University of Chinese Medicine, Suzhou, China, ${ }^{2}$ School of Pharmacy, Nanjing \\ University of Chinese Medicine, Nanjing, China, ${ }^{3}$ School of Pharmacy, Zhejiang Chinese Medicine University, Hangzhou, \\ China, ${ }^{4}$ School of Pharmacy, Henan University of Chinese Medicine, Zhengzhou, China
}

OPEN ACCESS

Edited by:

Hassan Karimi-maleh,

University of Electronic Science and

Technology of China, China

Reviewed by:

$\mathrm{LiFu}$,

Hangzhou Dianzi University, China

Vahid Arabali,

Islamic Azad University Sari

Branch, Iran

*Correspondence:

Xiaopeng Wang

wxpeng2004@163.com

Ting Zuo

381165010@qq.com

tThese authors have contributed equally to this work

Specialty section:

This article was submitted to Electrochemistry,

a section of the journal

Frontiers in Chemistry

Received: 25 June 2020

Accepted: 20 July 2020

Published: 11 September 2020

Citation:

Yan S, Yue Y, Su L, Hao M, Wang X and Zuo T (2020) Development of Electrochemical Oscillation Method for

Identification of Prunus persica,

Prunus davidiana, and Prunus armeniaca Nuts. Front. Chem. 8:748.

doi: 10.3389/fchem.2020.00748
In this work, an electrochemical oscillation system has been developed using the Belousov-Zhabotinsky reaction. The effect of the combination of each reagent, reaction temperature, and stirring speed on the induction period, oscillating period, and oscillating life were optimized. The nuts of Prunus persica, Prunus davidiana, and Prunus armeniaca have been widely used for medical purposes. The proposed electrochemical oscillation system was then used for the identification of $P$. persica, $P$. davidiana, and $P$. armeniaca. Three nuts exhibited very different electrochemical oscillation profiles. The dendrogram was divided into three main principal infrageneric clades. Each cluster only contains one species, suggesting that no outlier was observed in this study. Based on the discussed results, we proposed a simple method for herbal medicine identification.

Keywords: electrochemical oscillation, Belousov-Zhabotinsky, plant identification, herbal medicine, Prunus spp.

\section{INTRODUCTION}

The fingerprint of traditional herbal medicine refers to the map of common peaks that can mark the characteristics of the traditional herbal medicine after proper pretreatment with a certain analysis method (Xie et al., 2006; Zhu et al., 2016; Wang et al., 2017). It is the visual characterization of the physical and chemical information of the traditional herbal medicine (Donno et al., 2016; Deconinck et al., 2017; Afshar et al., 2020; Fu et al., 2020; Karimi-Maleh et al., 2020a,c; Li et al., 2020; Tavana et al., 2020). The fingerprint of traditional herbal medicine has two characteristics: (1) Through the characteristics of the fingerprint, it can identify the authenticity or origin of the sample. (2) The area or ratio of the main characteristic peaks on the fingerprint can effectively control the quality of traditional herbal medicine.

At present, the common fingerprints of traditional herbal medicine are thin layer chromatography fingerprint (Szeremeta et al., 2017; Sibug-Torres et al., 2019a,b), highperformance liquid chromatography fingerprint (Li et al., 2016; Xue et al., 2017; Esteki et al., 2019), gas chromatography fingerprint (Aliakbarzadeh et al., 2016; Shekari et al., 2018; Huang et al., 2019), high-performance capillary electrophoresis fingerprint (Hou et al., 2019; Sun et al., 2019), high-speed countercurrent chromatography fingerprint (Gan et al., 2016; Wang et al., 2020), ultraviolet fingerprint, infrared fingerprint (Custers et al., 2017; Dai et al., 2019), nuclear magnetic resonance fingerprint (Sun et al., 2018; Flores et al., 2020), mass spectrometry fingerprint (Yang and Deng, 2016; Kharbach et al., 2020), X-ray diffraction fingerprint (Chen et al., 2017; Devi et al., 2017), immunoassay fingerprint 
(Cui et al., 2019), and DNA fingerprint (Pawar et al., 2017; Selvakumari et al., 2017). These methods can be used for in-depth research on traditional herbal medicine, but proper pretreatment of traditional herbal medicine is required. The pretreatment process will cause the loss of ingredients, so the existing fingerprint is actually only a collection of information on the chemical composition of some herbal medicines, not a complete reflection of the chemical composition of herbal medicines. Therefore, it is a primary task to explore a direct operation method of fingerprints that can be applied to the cluster characterization of traditional herbal medicine chemical components in various phases and dosage forms without pretreatment operations such as separation and purification. The discovery of nonlinear chemical phenomena has opened the study of complex systems. Due to the good reproducibility of the oscillating response, its application research is becoming more and more extensive, which provides a new idea and method for solving this problem.

At present, the Belousov-Zhabotinsky (B-Z) oscillation reaction is most widely used in analysis and detection, followed by the copper ion oscillation system (Alfifi et al., 2016; Luiz Fernando Oliveira Maia et al., 2019; Nawabi et al., 2019; Ullah et al., 2019). There are also Bray-Liebhafsky oscillation reaction, Briggs-Rauscher oscillation reaction, peroxidaseoxidase biochemical oscillator (peroxidase-oxidase oscillation system), and liquid membrane oscillator (Mukouyama et al., 2016; Bai et al., 2017; Peng et al., 2017; Chan and Dow, 2019; Ding et al., 2019). The basis for applying chemical oscillation reaction to analysis and detection is that the substance to be tested can interfere with the oscillation reaction. Different chemical oscillation reactions have different characteristics, and the shape of the potential-time (E-t) curve and various characteristic information parameters are also different (Miyazaki et al., 2016; Zhou et al., 2020). Herbal medicines of different types or origins and sources contain different chemical components and content. When the herbal medicine is added to the chemical oscillation system, the interference to the induction phase and the oscillation phase may be different from the effects of various substances in the oscillation system, causing different changes. By comparing the different changes of the E-t curve after adding different herbal medicines to the chemical oscillation system, not only the corresponding E-t curve is completely different from the curve of the blank system under the same experimental conditions, but more importantly, it reflects the chemical composition characteristics of different herbal medicine (Jin and Shen, 2017; Mohtashami et al., 2018). The fingerprint can be used to analyze the chemical composition of herbal medicine as a whole and to identify or qualitatively analyze herbal medicine. Electrochemistry has been widely used for sensing purpose in pharmaceutic fields (Fu et al., 2019; Fouladgar et al., 2020; Karimi-Maleh et al., 2020b; Mohanraj et al., 2020; Xu et al., 2020; Ying et al., 2020; Zabihpour et al., 2020). In this work, we proposed an electrochemical oscillation system based on $\mathrm{B}-\mathrm{Z}$ reaction. The effect of a combination of each reagent, reaction temperature, and stirring speed on the induction period, oscillating period, and oscillating life were optimized. The nuts

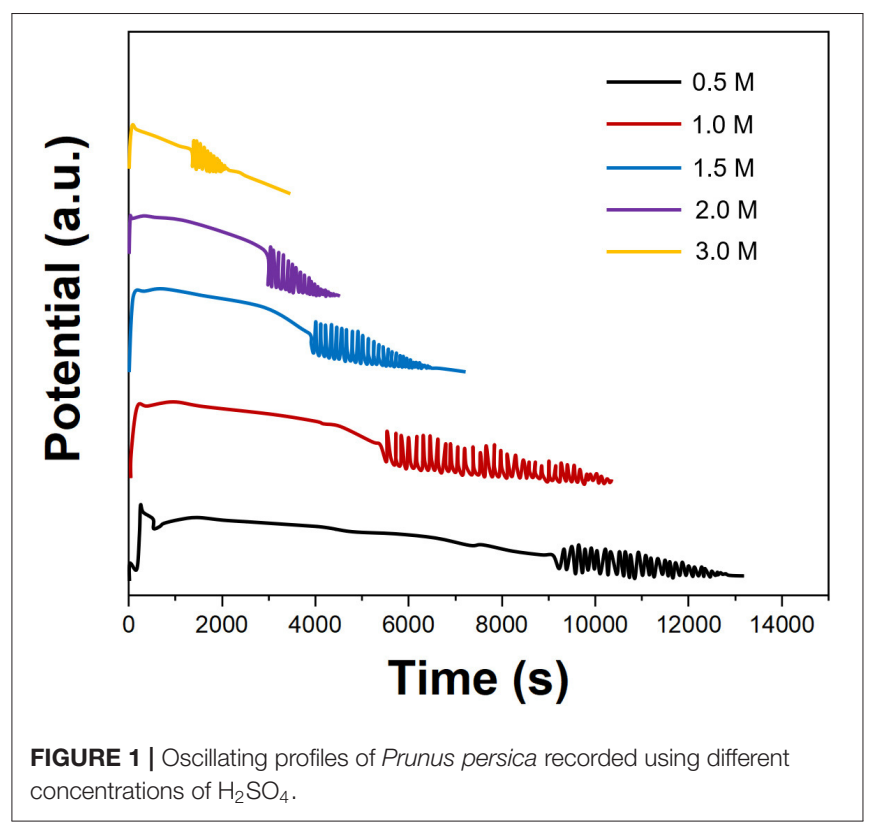

of Prunus persica, Prunus davidiana, and Prunus armeniaca have been selected as samples.

\section{MATERIALS AND METHODS}

All chemicals were analytical grade and used without purification. The nuts of $P$. persica, $P$. davidiana, and $P$. armeniaca were purchased from a local pharmacy and grounded into a powder. The chemical oscillating reaction is carried out in a continuously stirred jacketed reactor. The experimental temperature is controlled at $310 \mathrm{~K}$. A certain amount of herbal machines was added into the discussed reactor with different concentrations of $\mathrm{H}_{2} \mathrm{SO}_{4}(10 \mathrm{ml}), \mathrm{CH}_{3} \mathrm{COCH}_{3}(5 \mathrm{ml})$, and $\mathrm{MnSO}_{4}(5 \mathrm{ml})$. The mentioned solution was stirred $10 \mathrm{~min}$ before injection of $5-\mathrm{ml} \mathrm{KBrO}_{3}$. The E-t curve was monitored all the time until potential oscillation disappears. All electrochemical experiments were recorded using a CHI760E working station.

\section{RESULTS AND DISCUSSION}

Prunus persica has been used for optimizing the concentrations of all reagents used in the $\mathrm{B}-\mathrm{Z}$ reaction. Figure 1 shows the effect of the $\mathrm{H}_{2} \mathrm{SO}_{4}$ concentration on the electrochemical oscillation of $P$. persica. It can be seen that the oscillation profiles recorded after injection of $10 \mathrm{ml}$ of $\mathrm{H}_{2} \mathrm{SO}_{4}$ with different concentrations were different. When the sulfuric acid concentration was $1.0 \mathrm{M}$, the oscillation life is the longest, and the amplitude was the largest. When the sulfuric acid concentration exceeded $2.0 \mathrm{M}$, the oscillations decayed faster. When the sulfuric acid concentration was $0.5 \mathrm{M}$, the induction period of the oscillating reaction was too long. Therefore, we selected $1.0 \mathrm{M}$ of sulfuric acid for an oscillating reaction. 


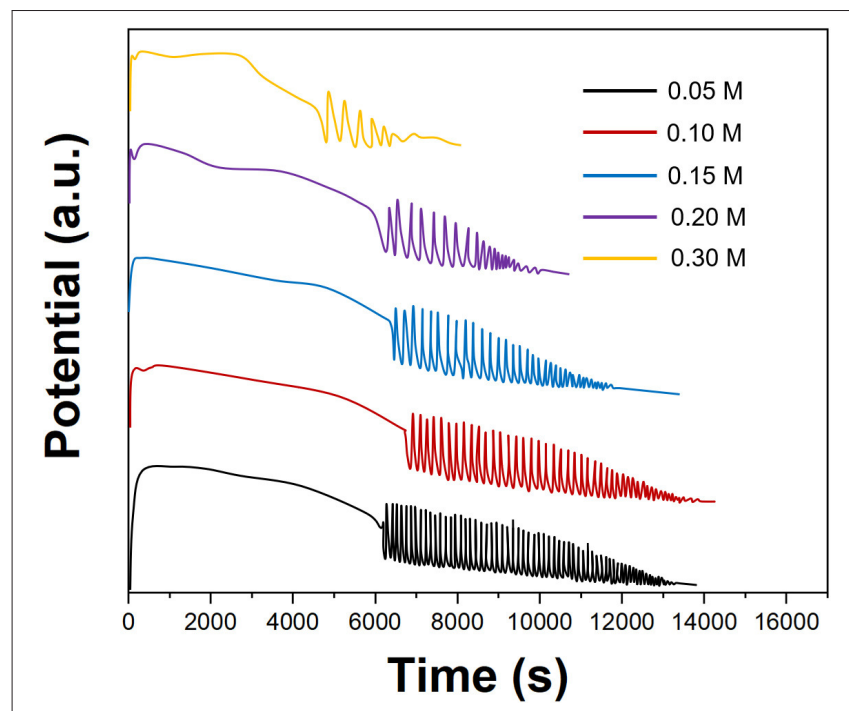

FIGURE 2 | Oscillating profiles of Prunus persica recorded using different concentrations of $\mathrm{MnSO}_{4}$.

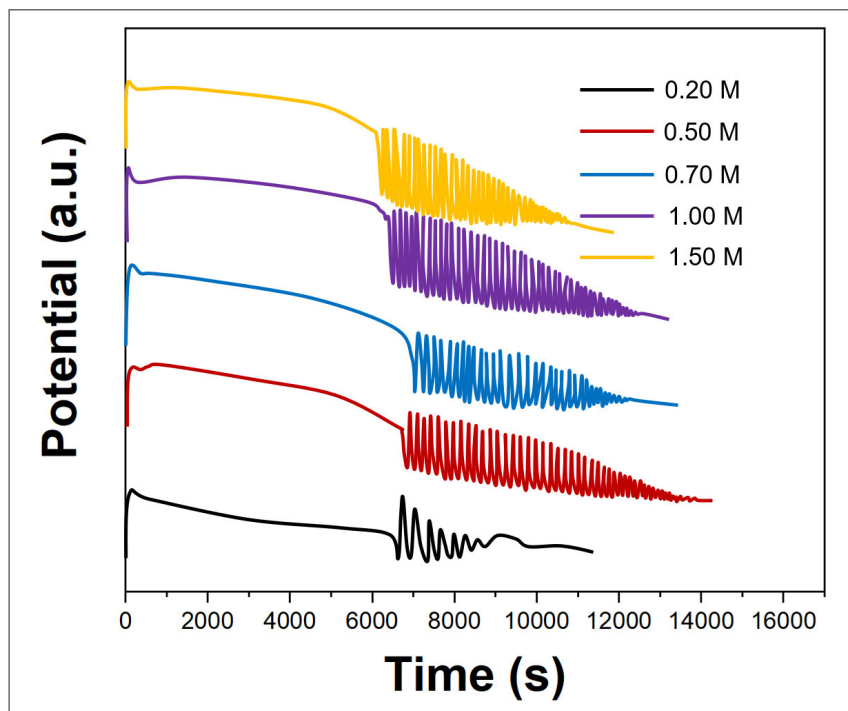

FIGURE 3 | Oscillating profiles of Prunus persica recorded using different concentrations of $\mathrm{CH}_{3} \mathrm{COCH}_{3}$.

Figure 2 shows the effect of the $\mathrm{MnSO}_{4}$ concentration on the electrochemical oscillation of $P$. persica. In this case, manganese ions were catalysts for oscillating reactions and had little effect on amplitude and induction time. Therefore, we selected $0.1 \mathrm{M}$ of $\mathrm{MnSO}_{4}$ for an oscillating reaction.

Figure 3 shows the effect of the $\mathrm{CH}_{3} \mathrm{COCH}_{3}$ concentration on the electrochemical oscillation of $P$. persica. When the concentration of $\mathrm{CH}_{3} \mathrm{COCH}_{3}$ was $0.2 \mathrm{M}$, the oscillation reaction is irregular; when the concentration of $\mathrm{CH}_{3} \mathrm{COCH}_{3}$ reaches $0.5 \mathrm{M}$, a regular oscillation reaction can be produced. $\mathrm{CH}_{3} \mathrm{COCH}_{3}$ can also produce normal oscillation response at higher concentrations. The role of $\mathrm{CH}_{3} \mathrm{COCH}_{3}$ was to
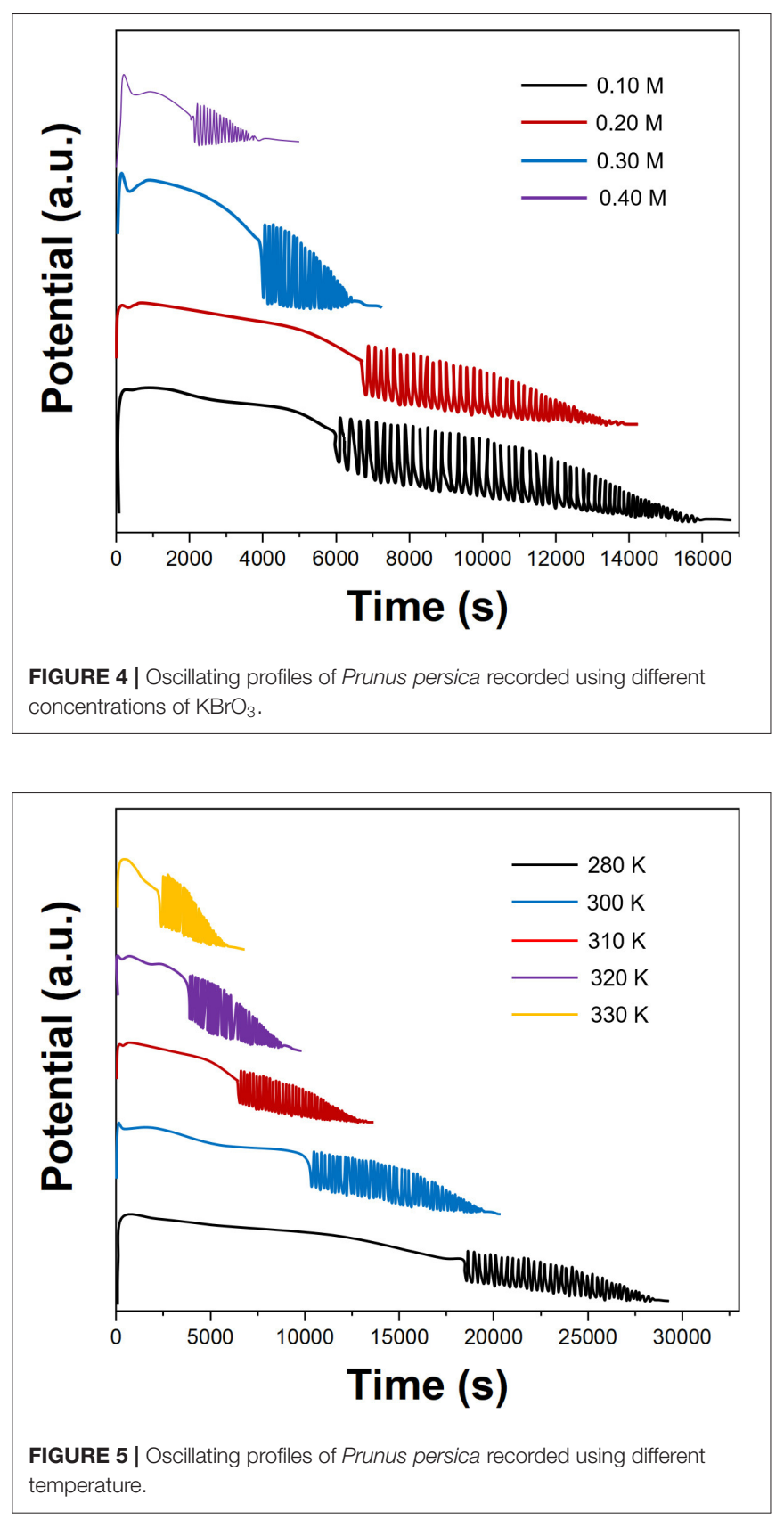

react with $\mathrm{Br}_{2}$ to form $\mathrm{CH}_{3} \mathrm{COCH}_{2} \mathrm{Br}$ to remove excess $\mathrm{Br}_{2}$. $\mathrm{CH}_{3} \mathrm{COCH}_{2} \mathrm{Br}$ is a toxic preparation, which is irritating to the eyes, so we selected $0.5 \mathrm{M}$ of $\mathrm{CH}_{3} \mathrm{COCH}_{3}$ for an oscillating reaction.

Figure 4 shows the effect of the $\mathrm{KBrO}_{3}$ concentration on the electrochemical oscillation of $P$. persica. It can be seen from Figure 4 that as the $\mathrm{KBrO}_{3}$ concentration increases, the maximum amplitude, induction time, and oscillation life increase. However, the solubility of $\mathrm{KBrO}_{3}$ at room temperature is small, so we selected $0.3 \mathrm{M}$ of $\mathrm{KBrO}_{3}$ for an oscillating reaction.

Figure 5 shows the effect of the temperature on the electrochemical oscillation of $P$. persica. The results show that as 
the temperature increases, the fingerprint data change in different patterns. Generally speaking, the higher the temperature, the longer the induction time, the shorter the oscillation period, the shorter the oscillation lifetime, and the larger the amplitude. Therefore, the selection of appropriate temperature conditions is of great significance for the control of reaction time, the stability of the fingerprint, and the reproducibility. Therefore, we selected $310 \mathrm{~K}$ for oscillating reactions.

Figure 6 shows the effect of the amount of $P$. persica on the electrochemical oscillation. When $P$. persica was $0.1 \mathrm{~g}$, the substrate that can be used as the $\mathrm{B}-\mathrm{Z}$ oscillation reaction was the least, so the induction period was the longest, and the oscillation period was also the longest. When its oscillating substrate was consumed, its oscillation suddenly stops. With the increase in the dosage of herbal medicine, the number of chemical components in the herbal medicine participating in the oscillation reaction also increased. The oscillation reaction was more likely to occur, so the reaction rate was accelerated, the induction period was reduced, and the oscillation period and oscillation life were also reduced. When the dosage of herbal medicine exceeds $0.5 \mathrm{~g}$, the front part of the curve becomes irregular, which was not conducive to the acquisition of characteristic information. When the dosage was small, the reaction time will become too long, requiring a longer analysis time. To obtain better information, the amount of herbal medicinal materials used in the fingerprints recording was $0.3 \mathrm{~g}$.

The reproducibility of electrochemical oscillation patterns for $P$. persica has been studied. The results indicated that under

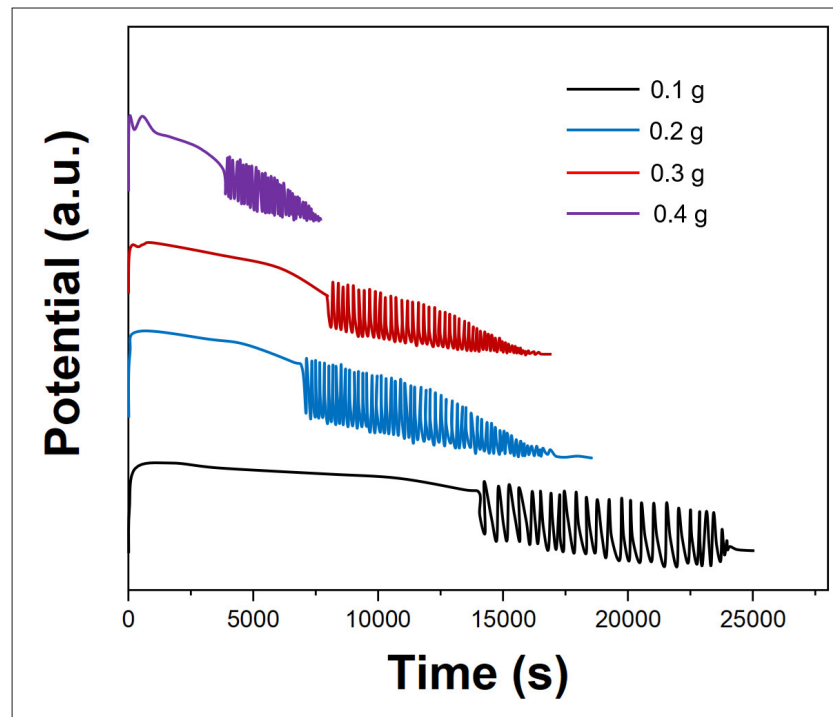

FIGURE 6 | Oscillating profiles recorded using different amount of Prunus persica.

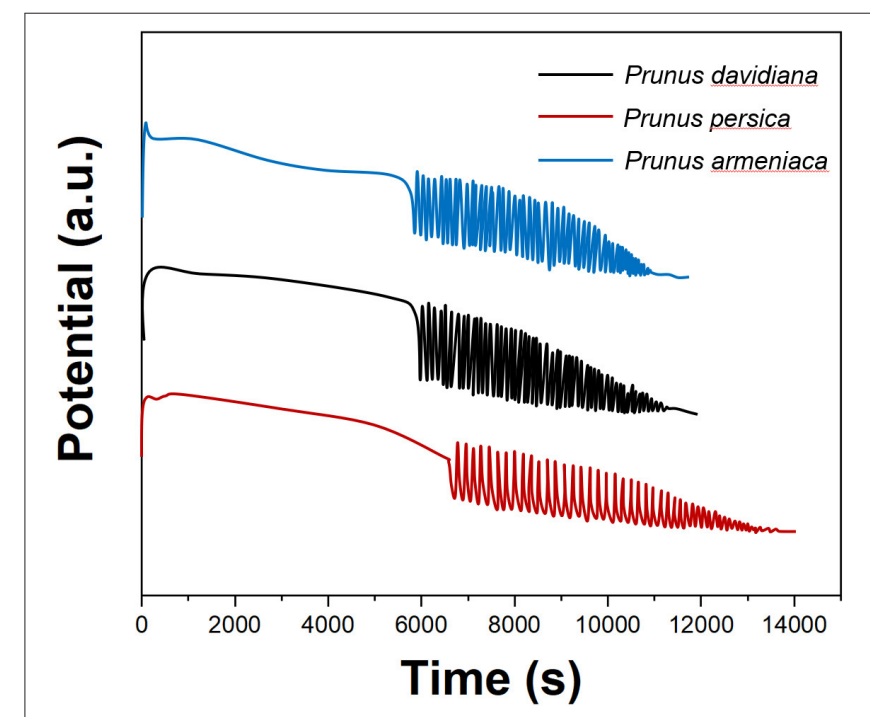

FIGURE 7 | Oscillating profiles recorded for Prunus persica, Prunus davidiana, and Prunus armeniaca.
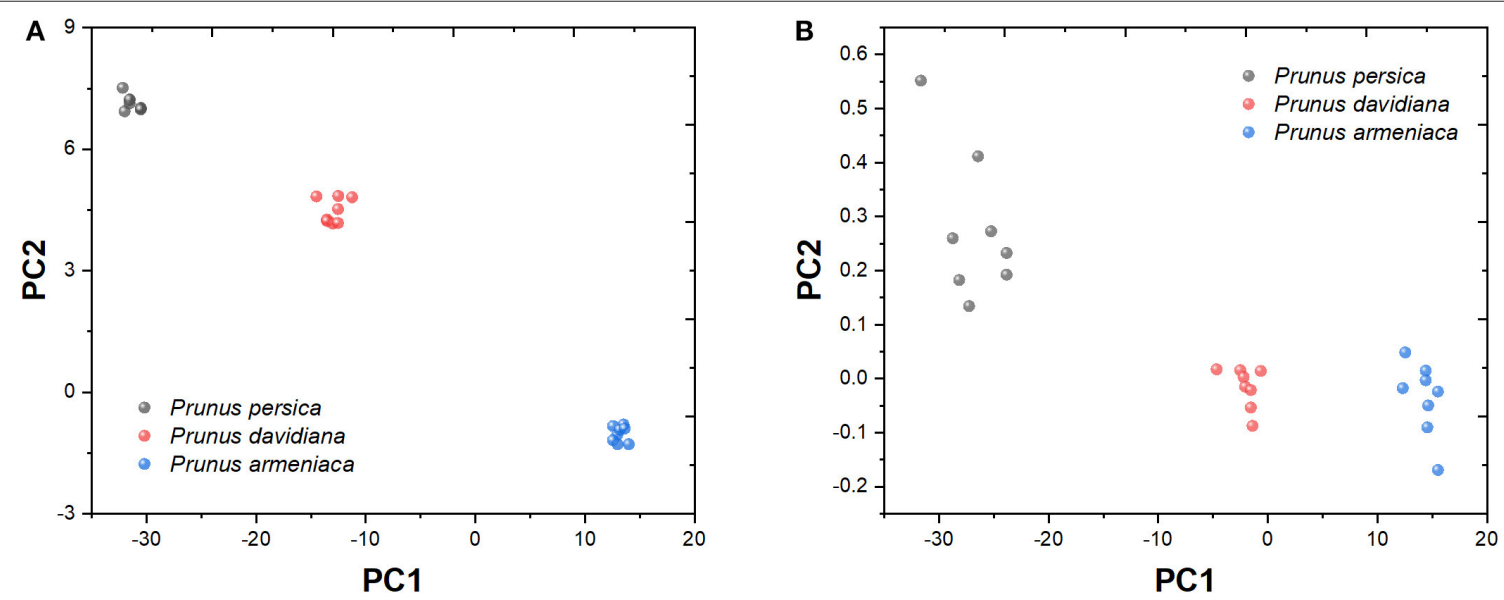

FIGURE 8 | Principal component analysis of Prunus persica, Prunus davidiana, and Prunus armeniaca. (A) PC1 vs. PC2. (B) PC1 vs. PC3. 
TABLE 1 | Eigenvalues and contributions of principle component.

\begin{tabular}{llll}
\hline PCA & Eigenvalue & $\begin{array}{l}\text { Contribution rate } \\
\text { (\%) }\end{array}$ & $\begin{array}{l}\text { Accumulating } \\
\text { contribution rate } \\
(\%)\end{array}$ \\
\hline PC1 & 0.588 & 89.44 & 89.44 \\
PC2 & 0.624 & 7.25 & 96.69 \\
PC3 & 0.007 & 3.31 & 100
\end{tabular}

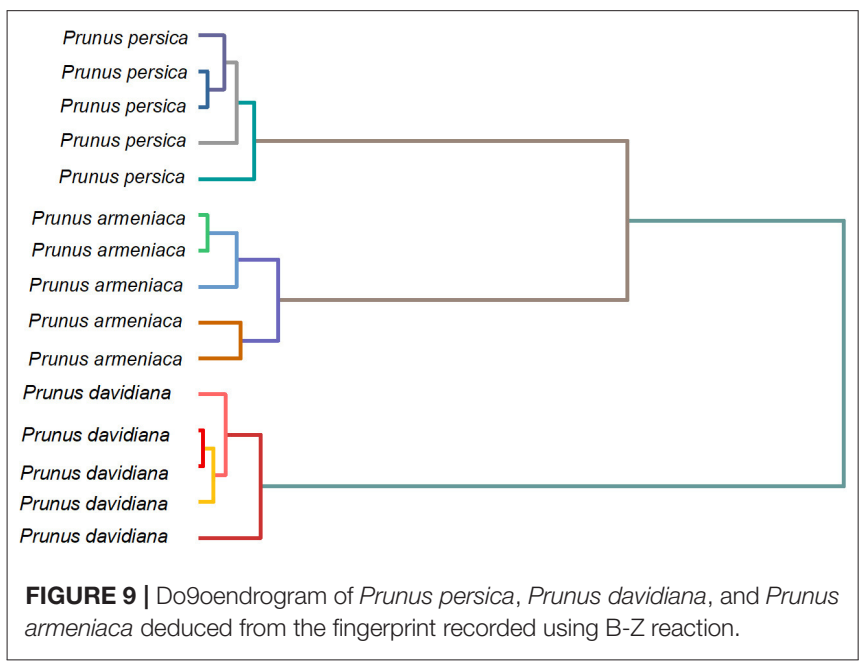

the same experimental conditions, the various indexes of the electrochemical oscillation measured are basically the same, RSD $\leq 2 \%$, indicating good reproducibility.

Figure 7 is the electrochemical fingerprint of $P$. persica, $P$. davidiana, and $P$. armeniaca. It can be seen that due to the different chemical components contained in different species, their participation in the oscillating reaction process is different, so the E-t curve induction time, oscillation life, maximum potential, start-up potential, and other data are different. At the same time, the shape of the induction curve and the oscillation curve are also different. These features help identify species.

Figure 8 shows the principal component analysis of $P$. persica, $P$. davidiana, and $P$. armeniaca recorded from different samples. Table 1 shows the characteristic value and contribution value of data after the principal component analysis. The contribution rates of the first three principal components were 89.44, 7.25, and $3.31 \%$, respectively. From the analysis in Figure 8A, it can be seen that the three samples can be distinguished obviously, whereas part of the data in Figure $\mathbf{8 B}$ is mutually charged.

\section{REFERENCES}

Afshar, S., Zamani, H. A., and Karimi-Maleh, H. (2020). NiO/SWCNTs coupled with an ionic liquid composite for amplified carbon paste electrode; A feasible approach for improving sensing ability of adrenalone and folic acid in dosage form. J. Pharm. Biomed. Anal. 188:113393. doi: 10.1016/j.jpba.2020.1 13393

Alfifi, H. Y., Marchant, T. R., and Nelson, M. I. (2016). Non-smooth feedback control for Belousov-Zhabotinskii reaction-diffusion
As the oscillating fingerprint of species is positively correlated with the distribution and amount of chemical compounds, we attempted to use the fingerprint, as mentioned earlier, for dendrogram analysis. Figure 9 shows the dendrogram of $P$. persica, $P$. davidiana, and $P$. armeniaca deduced from the fingerprint recorded using $\mathrm{B}-\mathrm{Z}$ reaction. The dendrogram was divided into three main principal infrageneric clades. Each cluster only contains one species, suggesting that no outlier was observed in this study. Based on the discussed results, we proposed a simple method for herbal medicines identification.

\section{CONCLUSION}

In this work, we proposed an authentication method based on the electrochemical oscillation system. B-Z reaction has been selected due to its high stability. The electrochemical oscillation profiles of $P$. persica, $P$. davidiana, and $P$. armeniaca were recorded. The recorded profile varies between the species due to the presence of different contents of chemical compounds. Based on the recorded oscillation fingerprint, these species can be effectively identified. Also, the dendrogram results suggest no outlier was observed in this study. Therefore, the proposed electrochemical oscillation can be used for herbal medicines identification.

\section{DATA AVAILABILITY STATEMENT}

The original contributions presented in the study are included in the article/supplementary material, further inquiries can be directed to the corresponding author/s.

\section{AUTHOR CONTRIBUTIONS}

SY, YY, and XW contributed conception and design of the study. LS and MH conducted electrochemical experiments. SY, XW, and TZ performed the statistical analysis. XW and SY wrote the manuscript. All authors contributed to manuscript revision, read, and approved the submitted version.

\section{FUNDING}

This work was funded by Natural Science Foundation of Jiangsu Province (BK20180219), National Natural Science Foundation of China (81804098), Jiangsu Youth Medical Talents Project (QNRC2016255), and Macao Young Scholars Program (AM2020020).

equations: semi-analytical solutions. J. Math. Chem. 54, 1632-1657. doi: 10.1007/s10910-016-0641-8

Aliakbarzadeh, G., Sereshti, H., and Parastar, H. (2016). Pattern recognition analysis of chromatographic fingerprints of Crocus sativus L. secondary metabolites towards source identification and quality control. Anal. Bioanal. Chem. 408, 3295-3307. doi: 10.1007/s00216-016-9400-8

Bai, H., Qing, S., Yang, D., Zhang, Y., Fan, X., and Tao, C. (2017). Periodic potential oscillation during oxygen evolution catalyzed by manganese oxide at constant current. J. Electrochem. Soc. 164:E78. doi: 10.1149/2.1241704jes 
Chan, P.-F., and Dow, W.-P. (2019). Spontaneous potential oscillation resulting in copper deposit with ultra-large grains. J. Electrochem. Soc. 166:D891.

Chen, D.-D., Xie, X.-F., Ao, H., Liu, J.-L., and Peng, C. (2017). Raman spectroscopy in quality control of Chinese herbal medicine. J. Chin. Med. Assoc. 80, 288-296. doi: 10.1016/j.jcma.2016.11.009

Cui, Y., Zhao, J., Zhou, J., Tan, G., Zhao, Q., Zhang, Y., et al. (2019). Development of a sensitive monoclonal antibody-based indirect competitive enzyme-linked immunosorbent assay for analysing nobiletin in citrus and herb samples. Food Chem. 293, 144-150. doi: 10.1016/j.foodchem.2019.04.101

Custers, D., Van Praag, N., Courselle, P., Apers, S., and Deconinck, E. (2017). Chromatographic fingerprinting as a strategy to identify regulated plants in illegal herbal supplements. Talanta 164, 490-502. doi: $10.1016 /$ j.talanta.2016.12.008

Dai, T., Yang, F., Liu, J., and Sun, G. (2019). Evaluation of the quality consistency of Zhenju Jiangya Tablets by systematic quantified fingerprint method in combination with antioxidant activity and three compounds analyses. Microchem. J. 150:104175. doi: 10.1016/j.microc.2019.104175

Deconinck, E., Djiogo, C. A. S., Kamugisha, A., and Courselle, P. (2017). The use of Stationary Phase Optimized Selectivity Liquid Chromatography for the development of herbal fingerprints to detect targeted plants in plant food supplements. Talanta 170, 441-450. doi: 10.1016/j.talanta.2017.04.028

Devi, G. K., Kumar, K. S., Parthiban, R., and Kalishwaralal, K. (2017). An insight study on HPTLC fingerprinting of Mukia maderaspatna: Mechanism of bioactive constituents in metal nanoparticle synthesis and its activity against human pathogens. Microb. Pathog. 102, 120-132. doi: 10.1016/j.micpath.2016.11.026

Ding, L., Song, Z., Wu, P., Cheng, J., Chen, C., Niu, Y., et al. (2019). Electrochemical oscillations during copper electrodissolution in hydrochloric acid solution. Int. J. Electrochem. Sci. 14, 585-597. doi: 10.20964/2019.01.63

Donno, D., Boggia, R., Zunin, P., Cerutti, A. K., Guido, M., Mellano, M. G., et al. (2016). Phytochemical fingerprint and chemometrics for natural food preparation pattern recognition: an innovative technique in food supplement quality control. J. Food Sci. Technol. 53, 1071-1083. doi: 10.1007/s13197-015-2115-6

Esteki, M., Shahsavari, Z., and Simal-Gandara, J. (2019). Food identification by high performance liquid chromatography fingerprinting and mathematical processing. Food Res. Int. 122, 303-317. doi: 10.1016/j.foodres.2019.04.025

Flores, I. S., Martinelli, B. C. B., and Lião, L. M. (2020). High-resolution magic angle spinning nuclear magnetic resonance (HR-MAS NMR) as a tool in the determination of biomarkers of Passiflora-based herbal medicines. Fitoterapia 142:104500. doi: 10.1016/j.fitote.2020.104500

Fouladgar, M., Karimi-Maleh, H., Opoku, F., and Govender, P. P. (2020). Electrochemical anticancer drug sensor for determination of raloxifene in the presence of tamoxifen using graphene-CuO-polypyrrole nanocomposite structure modified pencil graphite electrode: theoretical and experimental investigation. J. Mol. Liq. 311:113314. doi: 10.1016/j.molliq.2020.113314

Fu, L., Wu, M., Zheng, Y., Zhang, P., Ye, C., Zhang, H., et al. (2019). Lycoris species identification and infrageneric relationship investigation via graphene enhanced electrochemical fingerprinting of pollen. Sens. Actuators B Chem. 298:126836. doi: 10.1016/j.snb.2019.126836

Fu, L., Zheng, Y., Zhang, P., Zhang, H., Xu, Y., Zhou, J., et al. (2020). Development of an electrochemical biosensor for phylogenetic analysis of Amaryllidaceae based on the enhanced electrochemical fingerprint recorded from plant tissue. Biosens. Bioelectron. 159:112212. doi: 10.1016/j.bios.2020.112212

Gan, Z., Liang, Z., Chen, X., Wen, X., Wang, Y., Li, M., et al. (2016). Separation and preparation of 6-gingerol from molecular distillation residue of Yunnan ginger rhizomes by high-speed counter-current chromatography and the antioxidant activity of ginger oils in vitro. J. Chromatogr. B 1011, 99-107. doi: 10.1016/j.jchromb.2015.12.051

Hou, Z., Sun, G., Guo, Y., Yang, F., and Gong, D. (2019). Capillary electrophoresis fingerprints combined with Linear Quantitative Profiling Method to monitor the quality consistency and predict the antioxidant activity of Alkaloids of Sophora flavescens. J. Chromatogr. B 1133:121827. doi: 10.1016/j.jchromb.2019.121827

Huang, Y., Huang, Z., Watanabe, C., and Wang, L. (2019). Authentication of Schisandra chinensis and Schisandra sphenantherae in Chinese patent medicines by pyrolysis-gas chromatography/mass spectrometry and fingerprint analysis. J. Anal. Appl. Pyrolysis 137, 70-76. doi: 10.1016/j.jaap.2018.11.011
Jin, J. Z., and Shen, C. (2017). Study on electrochemical fingerprints of radix paeoniae alba. J. Chem. Soc. Pak. 39:947.

Karimi-Maleh, H., Cellat, K., Arikan, K., Savk, A., Karimi, F., and Sen, F. (2020a). Palladium-Nickel nanoparticles decorated on Functionalized-MWCNT for high precision non-enzymatic glucose sensing. Mater. Chem. Phys. 250:123042. doi: $10.1016 /$ j.matchemphys.2020.123042

Karimi-Maleh, H., Karimi, F., Malekmohammadi, S., Zakariae, N., Esmaeili, R., Rostamnia, S., et al. (2020b). An amplified voltammetric sensor based on platinum nanoparticle/polyoxometalate/two-dimensional hexagonal boron nitride nanosheets composite and ionic liquid for determination of N-hydroxysuccinimide in water samples. J. Mol. Liq. 310:113185. doi: 10.1016/j.molliq.2020.113185

Karimi-Maleh, H., Kumar, B. G., Rajendran, S., Qin, J., Vadivel, S., Durgalakshmi, D., et al. (2020c). Tuning of metal oxides photocatalytic performance using Ag nanoparticles integration. J. Mol. Liq. 314:113588. doi: 10.1016/j.molliq.2020.113588

Kharbach, M., Marmouzi, I., El Jemli, M., Bouklouze, A., and Vander Heyden, Y. (2020). Recent advances in untargeted and targeted approaches applied in herbal-extracts and essential-oils fingerprinting - a review. J. Pharm. Biomed. Anal. 177:112849. doi: 10.1016/j.jpba.2019.112849

Li, T., Zhuang, S., Wang, Y., Wang, Y., Wang, W., Zhang, H., et al. (2016). Flavonoid profiling of a traditional Chinese medicine formula of Huangqin Tang using high performance liquid chromatography. Acta Pharm. Sin. B 6, 148-157. doi: 10.1016/j.apsb.2016.01.001

Li, Y., Shen, Y., Yao, C., and Guo, D. (2020). Quality assessment of herbal medicines based on chemical fingerprints combined with chemometrics approach: a review. J. Pharm. Biomed. Anal. 185:113215. doi: 10.1016/j.jpba.2020.113215

Luiz Fernando Oliveira Maia, R. E. L., Reis, C., Gonçalves Reis, C. D., de Carvalho Damasceno, O. I., and Teixeira dos Reis, L. G. (2019). Potentiometric determination of paracetamol in pharmaceutical formulations by the analyte pulse perturbation technique using Belousov-Zhabotinskii oscillating chemical reaction. J. Anal. Chem. 74, 1232-1238. doi: 10.1134/S1061934819120074

Miyazaki, K., Nakata, A., Lee, Y.-S., Fukutsuka, T., and Abe, T. (2016). Influence of surfactants as additives to electrolyte solutions on zinc electrodeposition and potential oscillation behavior. J. Appl. Electrochem. 46, 1067-1073. doi: 10.1007/s10800-016-0987-4

Mohanraj, J., Durgalakshmi, D., Rakkesh, R. A., Balakumar, S., Rajendran, S., and Karimi-Maleh, H. (2020). Facile synthesis of paper based graphene electrodes for point of care devices: a double stranded DNA (dsDNA) biosensor. J. Colloid Interface Sci. 566, 463-472. doi: 10.1016/j.jcis.2020. 01.089

Mohtashami, S., Rowshan, V., Tabrizi, L., Babalar, M., and Ghani, A. (2018). Summer savory (Satureja hortensis L.) essential oil constituent oscillation at different storage conditions. Ind. Crops Prod. 111, 226-231. doi: 10.1016/j.indcrop.2017.09.055

Mukouyama, Y., Kawasaki, H., Hara, D., Yamada, Y., and Nakanishi, S. (2016). Appearance of new oscillation (Named Oscillation $\mathrm{H}$ ) induced by $\mathrm{Na} 2 \mathrm{SO} 4$ and $\mathrm{K} 2 \mathrm{SO} 4$ in electroreduction of $\mathrm{H}_{2} \mathrm{O}_{2}$ on platinum. J. Electrochem. Soc. 164:H1. doi: 10.1149/2.0011702jes

Nawabi, M. Y., Waqar Uddin, G., Ullah, S., Fang, Z., and Sardar, S. (2019). Identification of two hetero-substituent-aromatic isomers of-4-and 7-hydroxy coumarin with the belousov-zhabotinsky oscillator. Int. J. Electrochem. Sci. 14, 8676-8685. doi: 10.20964/2019.09.08

Pawar, R. S., Handy, S. M., Cheng, R., Shyong, N., and Grundel, E. (2017). Assessment of the authenticity of herbal dietary supplements: comparison of chemical and DNA barcoding methods. Planta Med. 83, 921-936. doi: $10.1055 / \mathrm{s}-0043-107881$

Peng, H., Liu, Z., and Tao, C. (2017). Electrochemical oscillation of vanadium ions in anolyte. J. Electrochem. Sci. Eng. 7, 139-144. doi: 10.5599/jese.406

Selvakumari, E., Jenifer, J., Priyadharshini, S., and Vinodhini, R. (2017). Application of DNA fingerprinting for plant identification. JAIR 5, 149-151.

Shekari, N., Vosough, M., and Tabar Heidar, K. (2018). Chromatographic fingerprinting through chemometric techniques for herbal slimming pills: a way of adulterant identification. Forensic Sci. Int. 286, 213-222. doi: $10.1016 /$ j.forsciint.2018.03.022

Sibug-Torres, S. M., Padolina, I. D., Cruz, P., Garcia, F. C., Garrovillas, M. J., Yabillo, M. R., et al. (2019a). Smartphone-based image analysis and chemometric pattern recognition of the thin-layer 
chromatographic fingerprints of herbal materials. Anal. Methods 11, 721-732. doi: 10.1039/C8AY02698J

Sibug-Torres, S. M., Padolina, I. D., and Enriquez, E. P. (2019b). Radial multistationary phase thin-layer chromatography for the field-ready fingerprinting of herbal materials. Anal. Methods 11, 5511-5520. doi: 10.1039/C9AY01714C

Sun, L., Wang, M., Ren, X., Jiang, M., and Deng, Y. (2018). Rapid authentication and differentiation of herbal medicine using $1 \mathrm{H}$ NMR fingerprints coupled with chemometrics. J. Pharm. Biomed. Anal. 160, 323-329. doi: 10.1016/j.jpba.2018.08.003

Sun, Y., Qian, M., Yuan, G., Yang, H., Cui, X., and Li, Y. (2019). High performance capillary electrophoresis characteristic fingerprint of schisandra chinensis. Curr. Pharm. Anal. 15, 456-464. doi: 10.2174/1573412914666180716143939

Szeremeta, D., Knaś, M., Długosz, E., Kowalska, T., and Sajewicz, M. (2017). Thin-layer chromatographic fingerprinting of the nonvolatile fraction extracted from the medicinal herb Cistus incanus L. J. Liq. Chromatogr. Relat. Technol. 40, 304-310. doi: 10.1080/10826076.2017.1298033

Tavana, T., Rezvani, A. R., and Karimi-Maleh, H. (2020). Pt-Pd-doped NiO nanoparticle decorated at single-wall carbon nanotubes: an excellent, powerful electrocatalyst for the fabrication of An electrochemical sensor to determine nalbuphine in the presence of tramadol as two opioid analgesic drugs. J. Pharm. Biomed. Anal. 189:113397. doi: 10.1016/j.jpba.2020.113397

Ullah, S., Uddin, W., Hu, G., Nawabi, M. Y., Ullah, R., Sardar, S., et al. (2019). Determination of ascorbic acid by using a Belousov-Zhabotinsky oscillating system catalyzed by a macrocylic complex. Int. J. Electrochem. Sci. 14, 5563-5572. doi: 10.20964/2019.06.07

Wang, C., Wang, L., Li, C., Hu, C., and Zhao, S. (2020). Anti-proliferation activities of three bioactive components purified by high-speed counter-current chromatography in essential oil from ginger. Eur. Food Res. Technol. 246, 795-805. doi: 10.1007/s00217-020-03446-7

Wang, Y., Liu, W., Yang, D., Qing, Y., Du, P., and Jin, Y. et al. (2017). UPLCMS/MS fingerprint of coptidis rhizoma-scutellariae radix herbal pair. Chin. J. Exp. Tradit. Med. Formulae 2017:14. doi: 10.1186/s13020-018-0171-3

Xie, P., Chen, S., Liang, Y., Wang, X., Tian, R., and Upton, R. (2006). Chromatographic fingerprint analysis-a rational approach for quality assessment of traditional Chinese herbal medicine. Plant Anal. 1112, 171-180. doi: 10.1016/j.chroma.2005.12.091

Xu, Y., Lu, Y., Zhang, P., Wang, Y., Zheng, Y., Fu, L., et al. (2020). Infrageneric phylogenetics investigation of Chimonanthus based on electroactive compound profiles. Bioelectrochemistry 133:107455. doi: 10.1016/j.bioelechem.2020.107455

Xue, Y., Zhu, L., and Yi, T. (2017). Fingerprint analysis of Resina Draconis by ultra-performance liquid chromatography. Chem. Cent. J. 11:67. doi: 10.1186/s13065-017-0299-8

Yang, Y., and Deng, J. (2016). Analysis of pharmaceutical products and herbal medicines using ambient mass spectrometry. TrAC Trends Anal. Chem. 82, 68-88. doi: 10.1016/j.trac.2016.04.011

Ying, J., Zheng, Y., Zhang, H., and Fu, L. (2020). Room temperature biosynthesis of gold nanoparticles with Lycoris aurea leaf extract for the electrochemical determination of aspirin. Rev. Mex. Ing. Quím. 19, 585-592. doi: 10.24275/rmiq/Mat741

Zabihpour, T., Shahidi, S.-A., Karimi-Maleh, H., and Ghorbani-HasanSaraei, A. (2020). An ultrasensitive electroanalytical sensor based on $\mathrm{MgO} / \mathrm{SWCNTs}$ 1-Butyl-3-methylimidazolium bis(trifluoromethylsulfonyl)imide paste electrode for the determination of ferulic acid in the presence sulfite in food samples. Microchem. J. 154:104572. doi: 10.1016/j.microc.2019.1 04572

Zhou, H., Zhang, N., Bai, H., Ming, H., Zhang, Q., Du, J., et al. (2020). A pulse modulatable self-oscillation kinetics for water oxidation at large current on manganese catalyst. Electrochimica Acta 337:135798. doi: 10.1016/j.electacta.2020.135798

Zhu, C.-S., Lin, Z.-J., Xiao, M.-L., Niu, H.-J., and Zhang, B. (2016). The spectrumeffect relationship - a rational approach to screening effective compounds, reflecting the internal quality of Chinese herbal medicine. Chin. J. Nat. Med. 14, 177-184. doi: 10.1016/S1875-5364(16)30014-0

Conflict of Interest: The authors declare that the research was conducted in the absence of any commercial or financial relationships that could be construed as a potential conflict of interest.

Copyright (C) 2020 Yan, Yue, Su, Hao, Wang and Zuo. This is an open-access article distributed under the terms of the Creative Commons Attribution License (CC BY). The use, distribution or reproduction in other forums is permitted, provided the original author(s) and the copyright owner(s) are credited and that the original publication in this journal is cited, in accordance with accepted academic practice. No use, distribution or reproduction is permitted which does not comply with these terms. 